\title{
The Impact of Transport Mode and Carbon Policy on Low-Carbon Retailer
}

\author{
Yi Zheng, ${ }^{1,2}$ Xue Yang, ${ }^{3}$ and Wen Jiang ${ }^{1}$ \\ ${ }^{1}$ School of Management and Economics, University of Electronic Science and Technology of China, Chengdu 611731, China \\ ${ }^{2}$ Department of Industrial Engineering, School of Construction and Management Engineering, Xihua University, \\ Chengdu 610039, China \\ ${ }^{3}$ Business School, Sichuan University, Chengdu 610065, China
}

Correspondence should be addressed to Yi Zheng; zhengyi@mail.xhu.edu.cn

Received 24 August 2015; Accepted 5 November 2015

Academic Editor: Amit Chakraborty

Copyright (C) 2015 Yi Zheng et al. This is an open access article distributed under the Creative Commons Attribution License, which permits unrestricted use, distribution, and reproduction in any medium, provided the original work is properly cited.

Low-carbon retail has become a strategic target for many developed and developing economies. This study discusses the impact of transport mode and carbon policy on achieving this objective. We investigated the retailer transportation mode, pricing, and ordering strategy, which all consider carbon-sensitive demand under the carbon cap-and-trade policy. We analyzed the optimal decision of retailer and their maximum profit affected by transport mode and cap-and-trade policy parameters. Results show that the two elements (cap-and-trade policy and consumer low-carbon awareness) could encourage the retailer to choose low-carbon transportation. The two elements also influence the profit and optimal decision of retailer. Finally, a numerical example is presented to illustrate the applicability of the model.

\section{Introduction}

Global warming has brought serious challenges to human life and development [1]. According to research, at least $90 \%$ of the effects of global warming are likely to be caused by human activities [2]. Excessive emission of greenhouse gases, such as $\mathrm{CO}_{2}$, is considered to be the main cause of global warming. To achieve energy saving and carbon reduction, the Chinese government reported in 2015 that carbon dioxide emissions have to be reduced by more than $3.1 \%$ this year, green healthy lifestyle promotion must be strengthened, and environmental awareness of consumers must be constantly improved. In recent years, low-carbon consumption has become increasingly popular with the enhancement of lowcarbon environmental awareness.

Some factors promote carbon reductions. First, consumers would like to pay more to buy low-carbon products [3]. Therefore, carbon emission of products directly affects consumer effectiveness and becomes one of the most important factors that affect market demands; that is, customer demand is emission-sensitive when the quantities of carbon emission are different from each other, thereby affecting retailer profit. The retailer can sell more environmental products with lower carbon emissions to improve the profit level. Second, cap-and-trade policy, which is enforced by the local government, has become an important regulation adopted by many countries to control carbon emissions. Under this policy, the government sets a free carbon quota for each company. If this free carbon quota is insufficient for carbon emissions, the company should buy more allowance from the carbon market or sell its extra quotas in the carbon market to gain profit. Retailer profit and decision-making are affected by this policy. In general, retailer strategies should consider the emission-sensitive demand from customers and cap-andtrade policy compulsively executed by the government.

Consumers who purchase low-carbon products can make enterprises conserve energy and reduce carbon emissions during production, storage, and transportation. The enterprise also takes reduction of carbon emission as an important operational index for decision-making. Under the product improvement and sustainable development plan, Wal-Mart suppliers reduced $20 \%$ of unit product energy during production and transportation in 2012 compared with 2007. Many enterprises such as Danone and Louis Vuitton take 
low-carbon decision as one of their most significant commercial strategies [4]. Empirical studies indicate that 50\%$60 \%$ and $30 \%-40 \%$ of carbon emissions are produced during production and transportation, respectively. Many studies on carbon emission reduction in production are currently available. However, few of them consider carbon emission reduction in transportation, which is the second largest carbon emission source of products [5].

In this study, we consider customer emission-sensitive demand and cap-and-trade policy, as well as using a twostage game model, to create a strategic decision for retailers on transport mode, pricing, and ordering. Moreover, to compare the model with cap-and-trade policy and that without carbon reduction policy, we design two structures to support our argument. The first structure only has customer emission-sensitive demand and not a carbon cap-and-trade policy, whereas the second involves both customer emissionsensitive demand and cap-and-trade policy. To the best of our knowledge, no research on how to select transport mode has examined the impact of transport mode selection on the decisions of low-carbon retailers under carbon policy and customer emission-sensitive demand. The present study aims to fill this research gap by addressing the following key questions:

(1) How can a pricing policy and an ordering and transport mode selection strategy be developed for the retailer to maximize profit while minimizing the negative environmental impact under cap-and-trade policy and customer emission-sensitive demand?

(2) What effect do the retailer's cost of transport process and the carbon emissions of transport process efficiencies have on the optimal price, optimal ordering quantity, and maximum profits?

(3) What impact does customer emission-sensitive demand have on low-carbon retailer's pricing strategy, ordering strategy, and maximum expected profit?

To solve these questions, we research one monopolistic retailer under cap-and-trade policy and consumer emissionsensitive demand. The retailer transports a product and sells it to consumer with a deterministic demand affected by the retail price and unit carbon emissions. Using the games, we attempt to derive the optimal pricing policy, transport mode, and ordering policy for one monopolistic retailer. We also examine the impact of the transport mode, carbon trade price, and initial carbon cap on the optimal policies and maximum profit of retailers by comparing the optimal solutions. This study intends to understand the impact of carbon capand-trade policy and consumer emission-sensitive demand for low-carbon retailers.

The rest of this paper is organized as follows: the literature is reviewed in Section 2. Section 3 describes the problem and assumptions. The pricing, transport mode, and ordering quantity policy in the model are discussed in Section 4 under consumer emission-sensitive demand only and under capand-trade policy with consumer emission-sensitive demand. Sensitivity analysis is discussed in Section 5, and the impacts of emission-sensitive demand and cap-and-trade policy are discussed in Section 6. Section 7 provides numerical examples to demonstrate the validity of the models, and a numerical example is discussed. Finally, we discuss the conclusions and future research work in Section 8.

\section{Literature Review}

Choosing low-carbon operations and reducing greenhouse gas emissions are important strategies of modern enterprises to address the problem of global warming. Many scholars have investigated the issue of low-carbon emissions and operations. The literature reviewed in this section primarily relates to three streams: retailer pricing and ordering decisions, models with carbon emission, and influence of consumer price and emission-sensitive demand.

Chen [6] examined the retailer ordering strategy based on the change of wholesale price and determined the optimal ordering and corresponding regulation strategies. Tang and Kouvelis [7] studied dual-source and monophyletic purchasing strategies and the critical conditions of two retailers in Cournot duopoly competition. Abad $[8,9]$ determined the dynamic pricing and lot sizing problem under limited production and partial backlogging. Shah and Raykundaliya [10] considered that suppliers offer a delay in payment to settle the accounts due against a retailer, who determines the optimal retail price and ordering quantities to maximize profit. Shinn and Hwang [11] analyzed the retailer who has to decide the retail price and order quantities under the issue of an order size dependent delay in payments. Ekicia et al. [12] study a duopolistic market of supply competition for the retailer's order period and the number of annual costs from each supplier to minimum and show that a supplier may set a "threshold price" to occupy the entire market if its per unit fixed ordering cost is adequately small. Liu and $\mathrm{Yu}$ [13] examine that customers have fairness judgments about the sell price that will affect their shopping decisions.

In recent years, an increasing number of scholars have examined some carbon emission-related issues. The capand-trade mechanism has many advantages by introducing market policies with effective implementation [14]. For instance, Benjaafar et al. [15] provided insights that highlight the impact of procurement, production, and inventory operational decisions on carbon emissions. Studying the operations of supply chain considering theoretical and practical emission factors is still at its early stage. Stranlund [16] strongly recommended that effective trading programs should be implemented to meet the environmental standard. Ramudhin et al. [17] studied a steel supply chain model by leveraging the opportunities provided by the carbon emission trading market. Hua et al. [18] studied an EOQ model with pricing and carbon trading decisions. Chang et al. [19] consider a monopolist manufacturer under carbon cap-andtrade mechanism that makes new products in the first period and makes new and refabricated products simultaneously in the next period and the manufacturer has to make the decision on the optimal production quantities for the first and the second period. He et al. [20] focus on how to get the optimal production planning confronting two typical carbon 
emission policies for a complex supply chain facing stochastic market demands and design optimization algorithm to solve the joint optimal production problem.

Numerous scholars have attempted to investigate the effectiveness of the carbon cap-and-trade policy. Murray et al. [21] and Shammin and Bullard [22] studied the impact of this policy in reducing carbon dioxide on individual households and concluded that a flexible cap makes the trade system effective. Jiang and Klabjan [23] studied a setting in carbon trading pricing and demand which are stochastic and considered production and emission reduction investment decisions under the carbon cap-and-trade policy.

Consumers are willing to pay higher prices for lowcarbon products when they possess higher environmental awareness [3]. According to the surveys of the European Commission, when buying products, $83 \%$ of Europeans pay great attention to the impact of products on the environment. Researchers such as Tang and Zhou [24], Young et al. [25], Mahenc [26], and Blengini and Shields [27] pointed out that the demand for some products has become important in relation to environmental performance and affected the purchase decisions in the consumer market today. Moon et al. [28] collected consumer surveys to address the issue of paying for goods produced with environmental stewardship and stated stronger willingness to pay for green products. Krass et al. [29] explored the importance of studying the relationship among greenness, demand, and product price.

Chen [30] pointed out that the low-carbon preference of consumers has a significant impact on the life pattern and operation strategy of an enterprise, as well as on the competition and cooperation among enterprises. Xie et al. [31] studied the reduction of supply chain emission composed of single carbon emission reduction suppliers and downstream retailers, as well as the decision-sharing problem when demands have sensibility of carbon emission. For the three supply chain networks of the two phases, Liu et al. [32] studied the impact of consumer carbon-sensitive awareness and competition between the manufacturer and retailer profitability in the supply chain network. Based on this study, Du et al. [5] found that enterprises in the supply chain can select different carbon emission strategies in actual sensitive situations of different consumers when consumers have carbon and price sensitivity. Altmann [33] presents a multiechelon, multiproduct, and linear programming supply chain design model according to the case of a German famous productive enterprise, which considers the impact of consumers demand on the environment of the delivered products, which can help enterprise to evaluate discrete investment decision in manufacture resources. Zhang et al. [34] focus on the impact of consumer carbon emission sensitivity on order quantities and channel coordination in a supply chain consisting of one manufacturer and one retailer. Hoen et al. $[35,36]$ first conducted a study on how to adjust the transportation mode in the supply chain for carbon emission reduction by measuring carbon emission of different transportation modes adopted by retailers based on real data. According to empirical analysis, adjustment of transportation modes can reduce $10 \%$ of carbon emission and only increase $0.7 \%$ of logistic cost. The enterprise must create a policy in accordance with the actual conditions and carbon emission policy.

To the best of our knowledge, the current research presents the first model of transport mode selection decision that includes the pricing and ordering problem under capand-trade policy and customer emission-sensitive demand. Furthermore, we focus on the producer and develop a model that considers cost and emissions in transportation.

\section{Model Descriptions and Assumptions}

This study considers that, under the cap-and-trade policy, one dominant retailer purchases one kind of product and sells it to customers who are sensitive to price and carbon emission. If the total carbon emission produced by products sold by retailers in a single cycle exceeds the initial carbon quota $E_{0}$ distributed to retailers by the government, then retailers can purchase extra carbon emission right at the price of $C_{e}$ in the carbon emission transaction market. Otherwise, retailers can sell the rest of the carbon emissions at the price of $C_{e}$. Meanwhile, the retailer can make a strategic decision on the transportation mode and retail price of the unit product and then determine the ordering quantity of products.

In this study, we only consider carbon emissions produced during transportation and not carbon emissions produced during production and storage. We assume that customers can directly observe carbon emissions produced during the transportation of unit products in a certain way (such as carbon footprint and green product attestation). We assume that product demands and carbon emissions of unit products have negative correlation with retail price; thus,

$$
D(p, e)=\alpha-\beta p-\gamma e,
$$

where $p$ is the retail price of unit products set by the retailer and $e$ is the carbon emission quantity of unit products during transportation. Parameters $\alpha, \beta$, and $\gamma$ show consumer market attributes and, respectively, denote the market scale, sensitivity of the unit product to the retail price in the market, and sensitivity of the unit product to carbon emission in the market. In this study, the demand is certain that carbon emissions produced during production and storage can be combined with initial demands $\alpha$.

Based on the preceding definitions, the following assumptions are made.

(1) Two transportation modes are present for selection, and the transportation mode can be distinguished by two indicators, namely, transportation cost and carbon emission.

(2) The cost of transportation mode 1 is higher than that of transportation mode 2, but the carbon emission of the unit product in transportation mode 1 is lower than that in transportation mode 2; that is, $c_{1}>c_{2}$ and $e_{1}<e_{2}$. If $\lambda$ is the transportation part of transportation mode 1 for all products ordered by the retailer, then $1-\lambda$ is the transportation part of transportation mode 2 . Therefore, comprehensive transportation cost and comprehensive transportation carbon emission of unit product can be calculated:

$$
\begin{aligned}
& c(\lambda)=\lambda c_{1}+(1-\lambda) c_{2}, \\
& e(\lambda)=\lambda e_{1}+(1-\lambda) e_{2} .
\end{aligned}
$$


The transportation mode decision of the retailer is then converted to decision $\lambda$. When $\lambda=1$, the retailer uses transportation mode 1 to transport all products; when $\lambda=$ 0 , the retailer uses transportation mode 2 to transport all products; and when $0<\lambda<1$, the retailer uses two transportation modes to complete product transportation. The decision variables of retailers are converted to $p, \lambda$, and $q$.

(3) Determination of the procurement price $w$ is not within the scope of this study.

(4) Other costs of retailer are not considered. The fixed ordering costs which are not relevant to ordering quantity can be included in $w$ and the variable costs which are relevant to ordering quantity can be included in transportation cost (i.e., $c_{1}$ or $c_{2}$ ).

\section{Analytical Model}

This study reviewed two streams: the optimal decision model of the retailer with carbon emission-sensitive demand only and the model with both carbon emission-sensitive demand and cap-and-trade policy.

\subsection{Case 1: Model with Customer Emission-Sensitive Demand} Only. This model focuses on the impact of consumer emission-sensitive demand only. Using the notations in Parameters and Variables and the above assumptions, the retailer profit function denoted as $\bar{\pi}(p, \lambda)$ is

$$
\bar{\pi}(p, \lambda)=(p-w-c(\lambda))(\alpha-\beta p-\gamma e(\lambda)) .
$$

$c(\lambda)$ and $e(\lambda)$ can meet the requirements of formulas (2).

In formula (3), the first and second partial derivatives for $p$ and $\lambda$ can be obtained as

$$
\begin{aligned}
\frac{\partial \bar{\pi}(p, \lambda)}{\partial p}= & -2 \beta p+\alpha+\beta w+\beta c(\lambda)-\gamma e(\lambda), \\
\frac{\partial^{2} \bar{\pi}(p, \lambda)}{\partial p^{2}}= & -2 \beta<0, \\
\frac{\partial \bar{\pi}(p, \lambda)}{\partial p}= & -\left(c_{1}-c_{2}\right)(\alpha-\beta p-\gamma e(\lambda)) \\
& -\gamma\left(e_{1}-e_{2}\right)(p-w-c(\lambda)), \\
\frac{\partial^{2} \bar{\pi}(p, \lambda)}{\partial p^{2}}= & 2 \gamma\left(c_{1}-c_{2}\right)\left(e_{1}-e_{2}\right)<0 .
\end{aligned}
$$

Proposition 1. For certain $\lambda$, the optimal retail price is unique, and the requirements of function of $\lambda$ can be met using

$$
\bar{p}^{*}=\frac{\alpha+\beta w}{2 \beta}+\frac{c(\lambda)}{2}-\frac{\gamma}{2 \beta} e(\lambda) .
$$
(A) proportional to transportation cost,
(B) inversely proportional to carbon emission,
(C) proportional to $\lambda$.

Proof. Based on formula (5), for certain $\lambda$, retailers have a unique optimal retail price. If $\partial \pi(p, \lambda) / \partial p=0$, then formula (8) can be obtained.

Based on formula (8), $d \bar{p}^{*} / d c=1 / 2>0, d \bar{p}^{*} / d e=$ $-\gamma / 2 \beta<0$, and $d \bar{p}^{*} / d \lambda=\left(c_{1}-c_{2}\right) / 2+(\gamma / 2 \beta)\left(e_{2}-e_{1}\right)>0$. Therefore, the conclusion of the proposition is true.

This proposition indicates that when different transportation modes are considered, the optimal retail price is unique. The optimal retail price increases as the transportation cost rises and then drops as the carbon emission rises. Thus, whether the optimal retail price will increase or not is decided by two forces, namely, transportation cost and carbon emission. The optimal retail price increases when the transportation cost is dominant. In this study, the optimal transportation mode is decided based on the result of $\lambda$. Greater $\lambda$ leads to higher transportation, whereas lower carbon emission leads to higher optimal retail price.

Sequence solution method is also used in this study. $\bar{p}^{*}=p(\lambda)$ is plugged into the retailer profit function to convert to maximizing decision related to single variable $\lambda: \max _{\lambda} \bar{\pi}(\bar{p}(\lambda), \lambda)$.

Proposition 2. Under the cap-and-trade policy and price sensitivity of consumer, the optimal decisions of the retailer are as follows:

$$
\begin{aligned}
\text { When } \beta\left(c_{1}-c_{2}\right) & \geq \gamma\left(e_{2}-e_{1}\right), \\
\lambda^{*} & =0, \\
\bar{p}^{*} & =\frac{\alpha+\beta w}{2 \beta}+\frac{c_{2}}{2}-\frac{\gamma}{2 \beta} e_{2}, \\
\bar{q}^{*} & =\frac{1}{2}\left(\alpha-\beta w-\beta c_{2}-\gamma e_{2}\right) ; \\
\text { When } \beta\left(c_{1}-c_{2}\right) & \leq \gamma\left(e_{2}-e_{1}\right), \\
\lambda^{*} & =1, \\
\bar{p}^{*} & =\frac{\alpha+\beta w}{2 \beta}+\frac{c_{1}}{2}-\frac{\gamma}{2 \beta} e_{1}, \\
\bar{q}^{*} & =\frac{1}{2}\left(\alpha-\beta w-\beta c_{1}-\gamma e_{1}\right) .
\end{aligned}
$$

Proof. Plug $\bar{p}^{*}=p(\lambda)$ into profit function to obtain $\bar{\pi}(\lambda)=$ $(\alpha-\beta w-\beta c(\lambda)-\gamma e(\lambda))^{2} / 4 \beta$. The second derivative is calculated to obtain $\bar{\pi}^{\prime}(\lambda)=-(1 / 2 \beta)\left[\beta\left(c_{1}-c_{2}\right)+\gamma\left(e_{1}-\right.\right.$ $\left.\left.e_{2}\right)\right](\alpha-\beta w-\beta c(\lambda)-\gamma e(\lambda))$ and $\bar{\pi}^{\prime \prime}(\lambda)=(1 / 2 \beta)\left[\beta\left(c_{1}-\right.\right.$ $\left.\left.c_{2}\right)+\gamma\left(e_{1}-e_{2}\right)\right]^{2}>0$. The maximum point of function $\pi(\lambda)$ is at the end point; that is, $\lambda=0$ or $\lambda=1$. Consider $\bar{\pi}(0)=$ $\left(\alpha-\beta w-\beta c_{2}-\gamma e_{2}\right)^{2} / 4 \beta, \bar{\pi}(1)=\left(\alpha-\beta w-\beta c_{1}-\gamma e_{1}\right)^{2} / 4 \beta$. Consider the following:

(1) When $\beta\left(c_{1}-c_{2}\right) \geq \gamma\left(e_{2}-e_{1}\right), \bar{\pi}(0) \geq \bar{\pi}(1)$ and $\lambda^{*}=0$. Plug $\lambda^{*}=0$ into formulas (1) and (8) to obtain $\bar{p}^{*}=$ $(\alpha+\beta w) / 2 \beta+c_{2} / 2-(\gamma / 2 \beta) e_{2}, \bar{q}^{*}=(1 / 2)(\alpha-\beta w-$ $\left.\beta c_{2}-\gamma e_{2}\right)$.

(2) When $\beta\left(c_{1}-c_{2}\right) \leq \gamma\left(e_{2}-e_{1}\right), \bar{\pi}(0) \leq \bar{\pi}(1)$ and $\lambda^{*}=1$. Plug $\lambda^{*}=1$ into formulas (1) and (8) to obtain 


$$
\begin{aligned}
& \bar{p}^{*}=(\alpha+\beta w) / 2 \beta+c_{1} / 2-(\gamma / 2 \beta) e_{1}, \bar{q}^{*}=(1 / 2)(\alpha- \\
& \left.\beta w-\beta c_{1}-\gamma e_{1}\right) .
\end{aligned}
$$

Although two transportation modes can be selected for transportation, retailer can select one transportation mode (with minimum transportation cost) to transport all products. The optimal transportation mode of retailer depends on the impact of different parameter values of the two transportation modes on demands. $\beta\left(c_{1}-c_{2}\right)$ can be expressed as the impact of the total cost with different values on demands because the total cost of the two transportation modes is expressed in the retail price. $\beta$ represents the sensitive degree of customer demand to the retail price. $\gamma\left(e_{1}-e_{2}\right)$ can be expressed as the impact of carbon emission difference between two transportation modes on demands, but the $\gamma$ parameter is sensitive to carbon emission of unit products. When the total cost has a stronger impact on consumer demands, retailers are likely to select the transportation mode with a weaker total cost impact, that is, transportation mode 2. When carbon emission has a stronger impact on consumer demands, retailers are likely to select the transportation mode with a weaker carbon emission impact, that is, transportation mode 1 .

4.2. Case 2: Model with Both Carbon Emission-Sensitive Demand and Cap-and-Trade Policy. The decision problem that retailers face is consumer emission-sensitive demand under the cap-and-trade policy. Based on the preceding notations and assumptions, the profit function of the retailer denoted as $\pi(p, \lambda)$ is

$$
\begin{aligned}
\pi(p, \lambda)= & \left(p-w-c(\lambda)-C_{e} e(\lambda)\right)(\alpha-\beta p-\gamma e(\lambda)) \\
& +C_{e} E_{0} .
\end{aligned}
$$

In formula (10), the first and second partial derivatives for $p$ and $\lambda$ are obtained as

$$
\begin{aligned}
& \frac{\partial \pi(p, \lambda)}{\partial p} \\
& \quad=-2 \beta p+\alpha+\beta w+\beta\left[c(\lambda)+C_{e} e(\lambda)\right]-\gamma e(\lambda), \\
& \frac{\partial^{2} \pi(p, \lambda)}{\partial p^{2}}=-2 \beta<0, \\
& \frac{\partial \pi(p, \lambda)}{\partial \lambda} \\
& \quad=-\left[\left(c_{1}-c_{2}\right)+C_{e}\left(e_{1}-e_{2}\right)\right](\alpha-\beta p-\gamma e(\lambda)) \\
& \quad-\gamma\left(e_{1}-e_{2}\right)\left(p-w-c(\lambda)-C_{e} e(\lambda)\right), \\
& \frac{\partial^{2} \pi(p, \lambda)}{\partial \lambda^{2}}=2 \gamma\left[\left(c_{1}-c_{2}\right)+C_{e}\left(e_{1}-e_{2}\right)\right]\left(e_{1}-e_{2}\right) .
\end{aligned}
$$

Proposition 3. For certain $\lambda$, the optimal retail price of retailers is unique, and the requirements of $\lambda$ function can be met as follows:

$$
p^{*}=p_{0}+\frac{c(\lambda)+C_{e} e(\lambda)}{2}-\frac{\gamma e(\lambda)}{2 \beta},
$$

where $p_{0}=(\alpha+\beta w) / 2 \beta$ is the optimal retail price when the transportation mode is not considered. Therefore,

(A) optimal retail price of retailers is proportional to transportation cost;

(B) optimal retail price of retailers is proportional to carbon trade price;

(C) when $\beta C_{e}>\gamma$, optimal retail price is proportional to carbon emission; when $\beta C_{e}<\gamma$, optimal retail price is inversely proportional to carbon emission.

Proof. Based on formula (12), retailers have a unique optimal retail price for certain $\lambda$. If $\partial \pi(p, \lambda) / \partial p=0$, formula (15) can be obtained. Consider $d p^{*} / d c=1 / 2>0 ; d p^{*} / d C_{e}=$ $e(\lambda) / 2>0$ means that the optimal retail price of retailers is proportional to transportation cost and carbon trade price. Consider $d p^{*} / \operatorname{de}(\lambda)=\left(\beta C_{e}-\gamma\right) / 2 \beta$; when $\beta C_{e}>\gamma$, $d p^{*} / d e(\lambda)>0$, and when $\beta<\gamma, d p^{*} / \operatorname{de}(\lambda)<0$, so when $\beta C_{e}>\gamma$, the optimal retail price is proportional to the carbon emission. Otherwise, when $\beta C_{e}<\gamma$, the optimal retail price is inversely proportional to the carbon emission.

According to Proposition 3, the optimal retail price is unique if the retailer determines the transportation mode. The optimal retail price increases as the transportation cost and carbon transaction price increase. When the carbon emission transaction price is the dominant factor for the retail price, the optimal retail price of retailer drops as the carbon emission decreases. When consumers pay significant attention to the greenness degree of the products, the optimal retail price increases as the carbon emission decreases.

Sequence solution method is used, wherein $p^{*}=p(\lambda)$ is plugged into the retailer profit function to convert to maximizing decisions related to single variable $\lambda$ : $\max _{\lambda} \pi(p(\lambda), \lambda)$.

Proposition 4. Under the carbon emission policy and price sensitivity of consumers, the optimal decisions of retailers are as follows:

$$
\begin{aligned}
& \text { When } \beta\left(c_{1}-c_{2}\right)+\beta C_{e}\left(e_{1}-e_{2}\right) \geq \gamma\left(e_{2}-e_{1}\right), \\
& \lambda^{*}=0, \\
& p^{*}=\frac{\alpha+\beta w}{2 \beta}+\frac{c_{2}+C_{e} e_{2}}{2}-\frac{\gamma}{2 \beta} e_{2}, \\
& q^{*}=\frac{1}{2}\left(\alpha-\beta w-\beta c_{2}-\beta C_{e} e_{2}-\gamma e_{2}\right) ; \\
& \text { When } \beta\left(c_{1}-c_{2}\right)+\beta C_{e}\left(e_{1}-e_{2}\right)<\gamma\left(e_{2}-e_{1}\right), \\
& \lambda^{*}=1, \\
& p^{*}=\frac{\alpha+\beta w}{2 \beta}+\frac{c_{1}+C_{e} e_{1}}{2}-\frac{\gamma}{2 \beta} e_{1}, \\
& q^{*}=\frac{1}{2}\left(\alpha-\beta w-\beta c_{1}-\beta C_{e} e_{1}-\gamma e_{1}\right) .
\end{aligned}
$$

Proof. By plugging $p^{*}=p(\lambda)$ into the profit function, we can obtain $\pi(\lambda)=(1 / 4 \beta)\left[\alpha-\beta w-\beta c(\lambda)-\beta C_{e} e(\lambda)-\gamma e(\lambda)\right]^{2}+C_{e} E_{0}$. 
For certain $\lambda, \pi^{\prime}(\lambda)=-(1 / 2 \beta)\left[\beta\left(c_{1}-c_{2}\right)+\beta C_{e}\left(e_{1}-e_{2}\right)+\right.$ $\left.\gamma\left(e_{1}-e_{2}\right)\right]\left(\alpha-\beta w-\beta c(\lambda)-\beta C_{e} e(\lambda)-\gamma e(\lambda)\right)$ and $\pi^{\prime \prime}(\lambda)=$ $(1 / 2 \beta)\left[\beta\left(c_{1}-c_{2}\right)+\beta C_{e}\left(e_{1}-e_{2}\right)+\gamma\left(e_{1}-e_{2}\right)\right]^{2}>0$. The maximum point of function $\pi(\lambda)$ is at the end point; that is, $\lambda=0$ or $\lambda=1$. Because $\pi(0)=\left(\alpha-\beta w-\beta c_{2}-\beta C_{e} e_{2}-\gamma e_{2}\right)^{2} / 4 \beta+$ $C_{e} E_{0}, \pi(1)=\left(\alpha-\beta w-\beta c_{1}-\beta C_{e} e_{1}-\gamma e_{1}\right)^{2} / 4 \beta+C_{e} E_{0}$, we can obtain the following:

(1) When $\beta\left(c_{1}-c_{2}\right)+\beta C_{e}\left(e_{1}-e_{2}\right) \geq \gamma\left(e_{2}-e_{1}\right)$ and $\pi(0) \geq \pi(1), \lambda^{*}=0$. By plugging $\lambda^{*}=0$ into formulas (15) and (6), we can obtain $p^{*}=(\alpha+\beta w) / 2 \beta+\left(c_{2}+\right.$ $\left.\beta C_{e} e_{2}\right) / 2-(\gamma / 2 \beta) e_{2}$ and $q^{*}=(1 / 2)\left(\alpha-\beta w-\beta c_{2}-\right.$ $\left.\beta C_{e} e_{2}-\gamma e_{2}\right)$.

(2) When $\beta\left(c_{1}-c_{2}\right)+\beta C_{e}\left(e_{1}-e_{2}\right)<\gamma\left(e_{2}-e_{1}\right)$ and $\pi(0)<\pi(1), \lambda^{*}=1$. By plugging $\lambda^{*}=1$ into formulas (15) and (6), we can obtain $p^{*}=(\alpha+\beta w) / 2 \beta+\left(c_{1}+\right.$ $\left.\beta C_{e} e_{1}\right) / 2-(\gamma / 2 \beta) e_{1}$ and $q^{*}=(1 / 2)\left(\alpha-\beta w-\beta c_{1}-\right.$ $\left.\beta C_{e} e_{1}-\gamma e_{1}\right)$.

Although both transportation modes can be selected for transportation, retailers can select only one transportation mode (with the minimum transportation cost) to transport all products. The optimal transportation mode of retailers depends on the impact of the different parameter values of two transportation modes on demands. $\beta\left[\left(c_{1}-c_{2}\right)+C_{e}\left(e_{1}-\right.\right.$ $\left.e_{2}\right)$ ] can be expressed as the impact of the total cost with different values (transportation cost plus carbon cost) on demands because the total cost of two transportation modes is expressed in the product retail cost. However, $\beta$ is the parameter where the demand is sensitive to the retail price of the unit product. $\gamma\left(e_{1}-e_{2}\right)$ can be expressed as the impact of carbon emission difference between two transportation modes on demands, but $\gamma$ is the parameter where consumer demands are sensitive to carbon emission of unit products. When the total cost has a stronger impact on consumer demands, retailers likely select the transportation mode with a weaker total cost impact, that is, transportation mode 2 . Likewise, when carbon emission has a stronger impact on the demand, retailers are likely to select the transportation mode with a weaker carbon emission impact, that is, transportation mode 1 .

\section{Sensitivity Analysis}

The impact of transportation mode on the optimal decision of retailers and maximum expected profit is explored to analyze the impact of carbon cap and carbon trade price. Sensitivity analysis related to the change of $E_{0}$ and $C_{e}$ and transportation mode is conducted for the optimal decision of retailers and maximum expected profit. Considering the preceding proposition, the retailer can select only one transportation mode; hence, the transportation mode 1 analysis is performed.

Thus, we can obtain the following propositions.

Proposition 5. Consider the following:

(1) $d q^{*} / d E_{0}=0 ; d p^{*} / d E_{0}=0$;

(2) $d q^{*} / d C_{e}<0 ; d p^{*} / d C_{e}>0$.
Proof. When $\beta\left(c_{1}-c_{2}\right)+\beta C_{e}\left(e_{1}-e_{2}\right) \geq \gamma\left(e_{2}-e_{1}\right), d q^{*} / d E_{0}=0$, $d p^{*} / d E_{0}=0, d q^{*} / d C_{e}=-\beta e_{2} / 2<0$, and $d p^{*} / d C_{e}=e_{2} / 2>$ 0 ; when $\beta\left(c_{1}-c_{2}\right)+\beta C_{e}\left(e_{1}-e_{2}\right) \leq \gamma\left(e_{2}-e_{1}\right), d q^{*} / d E_{0}=0$, $d p^{*} / d E_{0}=0, d q^{*} / d C_{e}=-\beta e_{1} / 2<0$, and $d p^{*} / d C_{e}=e_{1} / 2>$ 0 .

Proposition 5 indicates that, under the carbon cap-andtrade policy, the carbon emission cap distributed to retailers by the government does not impact the optimal ordering quantity of retailers and optimal pricing decision. Moreover, the rise of carbon emission transaction price is equivalent to the increase in carbon emission cost of products to reduce optimal ordering quantity of retailers and increase the retail price of products.

\section{Proposition 6. Consider the following:}

(1) $d p^{*} / d c_{1}>0$; when $\beta C_{e}-\gamma \leq 0, d p^{*} / d e_{1} \leq 0$ and when $\beta C_{e}-\gamma>0, d p^{*} / d e_{1}>0$;

(2) $d q^{*} / d c_{1}<0 ; d q^{*} / d e_{1}<0$.

Proof. (1) Consider $d p^{*} / d c_{1}=1 / 2$, so $d p^{*} / d c_{1}>0$. Consider $d p^{*} / d e_{1}=\left(\beta C_{e}-\gamma\right) / 2 \beta$. When $\beta C_{e}-\gamma \leq 0$, $d p^{*} / d e_{1} \leq 0$, and when $\beta C_{e}-\gamma>0, d p^{*} / d e_{1}>0$. (2) Consider $d q^{*} / d c_{1}=-\beta / 2$, so $d q^{*} / d c_{1}>0$. Therefore, $d q^{*} / d e_{1}=-\beta C_{e} / 2-\gamma / 2$, so $d q^{*} / d e_{1}<0$.

The first item shows that the optimal retail price is proportional to the transportation cost of unit products. The relationship between optimal retail price and carbon emission of unit product depends on the carbon emission sensitivity of customers. If the impact of carbon emission sensitivity on the retail price is larger than that of the carbon price, the optimal retail price is inversely proportional to the carbon emission of the unit product. Otherwise, the optimal retail price increases with carbon emission quantity. The reason is that the rise in transportation cost directly causes a decline in marginal profit. Thus, the retailer can increase the retail price to improve the profit.

The second item shows that the optimal ordering quantities of the retailer are inversely proportional to transportation cost and carbon emission quantity. If the increase in transportation cost and carbon emission cost increases the composite cost rise, the optimal ordering quantity decreases because the environmental awareness of consumers increases, thereby influencing the ordering quantity by carbon emission. Considering the first item, retailers adjusting the retail price can balance out recession in demand caused by carbon transportation of some unit products and carbon emission. However, this adjustment cannot balance out the impact of carbon emission on demands. Therefore, the optimal ordering quantity of the retailer still decreases.

Proposition 7. Consider the following:

(1) $d \pi\left(q^{*}, \lambda^{*}\right) / d E_{0}>0$;

(2) $d \pi\left(q^{*}, \lambda^{*}\right) / d C_{e}=E_{0}-e(\lambda) q^{*}$. 
Proof. Consider $\pi(p, \lambda)=\left(p-w-c(\lambda)-C_{e} e(\lambda)\right)(\alpha-\beta p-$ $\gamma e(\lambda))+C_{e} E_{0}$, so $d \pi\left(q^{*}, \lambda^{*}\right) / d E_{0}=C_{e}>0$.

When $\lambda^{*}=0, \pi(p, \lambda)=(1 / 2 \beta)\left(\alpha-\beta w-\beta c_{2}-\beta C_{e} e_{2}-\right.$ $\left.\gamma e_{2}\right)^{2}+C_{e} E_{0}$ and $d \pi\left(q^{*}, \lambda^{*}\right) / d C_{e}=E_{0}-e_{2}\left(\alpha-\beta w-\beta c_{2}-\right.$ $\left.\beta C_{e} e_{2}-\gamma e_{2}\right)=E_{0}-e_{2} q^{*}$.

When $\lambda^{*}=1, d \pi\left(q^{*}, \lambda^{*}\right) / d C_{e}=E_{0}-e_{1} q^{*}$.

This proposition shows that the retailer profit is directly related to the initial carbon emission quota of retailers. More initial quota means more profit. Meanwhile, the price of carbon emission also impacts retailer profit. If $E_{0}-e(\lambda) q^{*}>0$, then the carbon emission transaction price is proportional to retailer profit, and the enterprise can sell excess carbon emission to gain profit. If $E_{0}-e(\lambda) q^{*}<0$, then the carbon emission price is inversely proportional to the retailer profit. If $E_{0}-e(\lambda) q^{*}=0$, then the retailer profit is unrelated to the carbon emission price.

Proposition 8. Consider $d \pi\left(p^{*}, \lambda^{*}\right) / d c_{1}<0$ and $d \pi\left(p^{*}\right.$, $\left.\lambda^{*}\right) / d e_{1}<0$.

Proof. If $\lambda^{*}=1, \pi\left(p^{*}, \lambda^{*}\right)=\left(\alpha-\beta w-\beta c_{1}-\beta C_{e} e_{1}-\right.$ $\left.\gamma e_{1}\right)^{2} / 4 \beta+C_{e} E_{0}$, so $d \pi\left(p^{*}, \lambda^{*}\right) / d c_{1}=-\left(\alpha-\beta w-\beta c_{1}-\beta C_{e} e_{1}-\right.$ $\left.\gamma e_{1}\right) / 2<0$ and $d \pi\left(p^{*}, \lambda^{*}\right) / d e_{1}=-\left(\left(\beta C_{e}+\gamma\right) / 2 \beta\right)(\alpha-\beta w-$ $\left.\beta c_{1}-\beta C_{e} e_{1}-\gamma e_{1}\right)<0$. If $\lambda^{*}=0$, results are the same.

Proposition 8 shows that the maximum profit of retailers is inversely proportional to the transportation cost of unit products and carbon emission. With the rise in transportation cost and carbon emission of the unit product, the maximum profit of retailers decreases. When the environmental awareness of the customer is enhanced, the sensitivity for carbon emission is higher than that for transportation cost.

\section{Analysis and Discussions}

6.1. Effect of Customer Emission-Sensitive Demand. To analyze the impact of carbon sensitivity of customers on the optimal decision of retailers and maximum expected profit, we compared the optimal strategies of the retailer with and without carbon emission-sensitive demand.

When $\gamma=0$, that is, consumer carbon emission is not sensitive, the optimal transportation mode of the nonsensitive retailer to consumer carbon emission is expressed as $\overline{\bar{\lambda}}$ : when $\left(c_{1}-c_{2}\right) \geq C_{e}\left(e_{2}-e_{1}\right), \overline{\bar{\lambda}}=0$. When $\left(c_{1}-c_{2}\right)<C_{e}\left(e_{2}-e_{1}\right)$, $\overline{\bar{\lambda}}=1$.

Optimal pricing (expressed as $\overline{\bar{p}}) \overline{\bar{p}}=(\alpha+\beta w) / 2 \beta+(c(\overline{\bar{\lambda}})+$ $\left.C_{e} e(\overline{\bar{\lambda}})\right) / 2$, optimal ordering quantity (expressed as $\left.\overline{\bar{q}}\right) \overline{\bar{q}}=(\alpha-$ $\beta w) / 2-\beta c(\overline{\bar{\lambda}}) / 2-\beta C_{e} e(\overline{\bar{\lambda}}) / 2$, and maximum profit (expressed as $\overline{\bar{\pi}}) \overline{\bar{\pi}}=\left[\alpha-\beta w-\beta c(\overline{\bar{\lambda}})-\beta C_{e} e(\overline{\bar{\lambda}})\right]^{2} / 4 \beta$.

When the transportation mode selection strategy is compared under two conditions, namely, consumer carbon emission sensitivity and no sensitivity, the carbon emission sensitivity of consumers makes retailers select high transportation cost but low-carbon transportation mode. Consumers can guide retailers in selecting the transportation mode of low carbon and low emission reduction based on preference for low-carbon products.

Proposition 9. When $\lambda^{*}=\overline{\bar{\lambda}}, p^{*}<\overline{\bar{p}}, q^{*}<\overline{\bar{q}}$, and $\pi\left(q^{*}, \lambda^{*}\right)<\overline{\bar{\pi}}$

Proof. Based on the preceding conclusion, under the carbon quota and transaction policy, $p^{*}=(\alpha+\beta w) / 2 \beta+\left(c\left(\lambda^{*}\right)+\right.$ $\left.C_{e} e\left(\lambda^{*}\right)\right) / 2-(\gamma / 2 \beta) e\left(\lambda^{*}\right), q^{*}=(1 / 2)\left(\alpha-\beta w-\beta c\left(\lambda^{*}\right)-\right.$ $\left.\beta C_{e} e\left(\lambda^{*}\right)-\gamma e\left(\lambda^{*}\right)\right)$, and $\pi\left(q^{*}, \lambda^{*}\right)=\left[\alpha-\beta w-\beta c\left(\lambda^{*}\right)-\right.$ $\left.\beta C_{e} e\left(\lambda^{*}\right)-\gamma e\left(\lambda^{*}\right)\right]^{2} / 4 \beta+C_{e} E_{0}$. When no carbon sensitivity is considered, $\overline{\bar{p}}=(\alpha+\beta w) / 2 \beta+\left(c(\overline{\bar{\lambda}})+C_{e} e(\overline{\bar{\lambda}})\right) / 2, \overline{\bar{q}}=$ $(1 / 2)\left(\alpha-\beta w-\beta c(\overline{\bar{\lambda}})-\beta C_{e} e(\overline{\bar{\lambda}})\right)$, and $\overline{\bar{\pi}}=[\alpha-\beta w-\beta c(\overline{\bar{\lambda}})-$ $\left.\beta C_{e} e(\overline{\bar{\lambda}})\right]^{2} / 4 \beta+C_{e} E_{0}$.

When the same transportation mode is selected, $\lambda^{*}=\overline{\bar{\lambda}}$, $p^{*}-\bar{p}=-(\gamma / 2 \beta) e\left(\lambda^{*}\right)<0, q^{*}-\bar{q}=-\gamma e\left(\lambda^{*}\right) / 2<0$, and $\pi\left(q^{*}, \lambda^{*}\right)-\bar{\pi}=\left[\alpha-\beta w-\beta c\left(\lambda^{*}\right)-\beta C_{e} e\left(\lambda^{*}\right)-\gamma e\left(\lambda^{*}\right)\right]^{2} / 4 \beta-$ $\left[\alpha-\beta w-\beta c(\overline{\bar{\lambda}})-\beta C_{e} e(\overline{\bar{\lambda}})\right]^{2} / 4 \beta=-\gamma e\left(\lambda^{*}\right)\left[2 \alpha-2 \beta w-2 \beta c\left(\lambda^{*}\right)-\right.$ $\left.2 \beta C_{e} e\left(\lambda^{*}\right)-\gamma e\left(\lambda^{*}\right)\right] / 4 \beta<0$; that is, $p^{*}<\bar{p}, q^{*}<\bar{q}$, and $\pi\left(q^{*}, \lambda^{*}\right)<\bar{\pi}$.

Proposition 9 shows that when retailers select the same transportation mode, low-carbon product preference makes optimal retail price, ordering quantity, and profit lower than those under nonsensitivity to carbon emission. Under this condition, any transportation mode that produces carbon emission directly causes a decrease in demand, ordering quantity, and profit.

6.2. Effect of Cap-and-Trade Policy. Based on the preceding analysis, when $C_{e}=0, E_{0}=0$, that is, no carbon quota or transaction policy, we can obtain the optimal transportation mode under no carbon quota or transaction policy (expressed as $\bar{\lambda})$ : when $\beta\left(c_{1}-c_{2}\right) \geq \gamma\left(e_{2}-e_{1}\right), \bar{\lambda}=0$, and when $\beta\left(c_{1}-c_{2}\right)<$ $\gamma\left(e_{2}-e_{1}\right), \bar{\lambda}=1$.

Optimal pricing (expressed as $\bar{p}) \bar{p}=(\alpha+\beta w) / 2 \beta+$ $c(\bar{\lambda}) / 2-\gamma e(\bar{\lambda}) / 2 \beta$, optimal ordering quantity (expressed as $\bar{q}) \bar{q}=(\alpha-\beta w) / 2-\beta c(\bar{\lambda}) / 2-\gamma e(\bar{\lambda}) / 2$, and maximum profit (expressed as $\bar{\pi}) \bar{\pi}=[\alpha-\beta w-\beta c(\bar{\lambda})-\gamma e(\bar{\lambda})]^{2} / 4 \beta$.

We can obtain the following by comparing the transportation mode selection strategies under two conditions, namely, considering the carbon quota and transaction strategy and not considering the carbon quota and transaction strategy:

$$
\begin{aligned}
& \text { If } \beta\left(c_{1}-c_{2}\right) \geq\left(\gamma+\beta C_{e}\right)\left(e_{2}-e_{1}\right), \lambda^{*}=\bar{\lambda}=0, c(\lambda)=c_{2} . \\
& \text { If }\left(\gamma+\beta C_{e}\right)\left(e_{2}-e_{1}\right)>\beta\left(c_{1}-c_{2}\right) \geq \gamma\left(e_{2}-e_{1}\right), \lambda^{*}=1, \\
& \bar{\lambda}=0, c\left(\lambda^{*}\right)=c_{1} \text {, and } c(\bar{\lambda})=c_{2} . \\
& \text { If } \beta\left(c_{1}-c_{2}\right)<\gamma\left(e_{2}-e_{1}\right), \lambda^{*}=\bar{\lambda}=1, c(\lambda)=c_{1} .
\end{aligned}
$$

In this study, $c_{1}>c_{2}, e_{1}<e_{2}$, and the carbon quota and transaction policy can make retailers select high transportation cost but low-carbon emission mode. The carbon quota and transaction policy can realize the target of low carbon and emission reduction. 
Proposition 10. When $\lambda^{*}=\bar{\lambda}$,

(1) $p^{*}>\bar{p}, q^{*}<\bar{q}$.

(2) when $E_{0} \geq \beta C_{e} e\left(\lambda^{*}\right)\left[2 \alpha-2 \beta w-2 \beta c\left(\lambda^{*}\right)-\right.$ $\left.\beta C_{e} e\left(\lambda^{*}\right)-2 \gamma e\left(\lambda^{*}\right)\right] / 4 \beta C_{e}, \pi\left(q^{*}, \lambda^{*}\right) \geq \bar{\pi}$. When $E_{0}<\beta C_{e} e\left(\lambda^{*}\right)\left[2 \alpha-2 \beta w-2 \beta c\left(\lambda^{*}\right)-\beta C_{e} e\left(\lambda^{*}\right)-\right.$ $\left.2 \gamma e\left(\lambda^{*}\right)\right] / 4 \beta C_{e}, \pi\left(q^{*}, \lambda^{*}\right)<\bar{\pi}$.

Proof. Based on the preceding conclusion, under carbon quota and transaction policy, $p^{*}=(\alpha+\beta w) / 2 \beta+\left(c\left(\lambda^{*}\right)+\right.$ $\left.C_{e} e\left(\lambda^{*}\right)\right) / 2-(\gamma / 2 \beta) e\left(\lambda^{*}\right), q^{*}=(1 / 2)\left(\alpha-\beta w-\beta c\left(\lambda^{*}\right)-\right.$ $\left.\beta C_{e} e\left(\lambda^{*}\right)-\gamma e\left(\lambda^{*}\right)\right)$, and $\pi\left(q^{*}, \lambda^{*}\right)=\left[\alpha-\beta w-\beta c\left(\lambda^{*}\right)-\right.$ $\left.\beta C_{e} e\left(\lambda^{*}\right)-\gamma e\left(\lambda^{*}\right)\right]^{2} / 4 \beta+C_{e} E_{0}$; without carbon quota, $\bar{p}=$ $(\alpha+\beta w) / 2 \beta+c(\bar{\lambda}) / 2-\gamma e(\bar{\lambda}) / 2 \beta, \bar{q}=(\alpha-\beta w) / 2-\beta c(\bar{\lambda}) / 2-$ $\gamma e(\bar{\lambda}) / 2$, and $\bar{\pi}=[\alpha-\beta w-\beta c(\bar{\lambda})-\gamma e(\bar{\lambda})]^{2} / 4 \beta$.

When the same transportation mode is selected, $\lambda^{*}=\bar{\lambda}$, $p^{*}-\bar{p}=C_{e} e\left(\lambda^{*}\right) / 2>0$, and $q^{*}-\bar{q}=-\beta C_{e} e\left(\lambda^{*}\right) / 2<0$; that is, $p^{*}>\bar{p}>0,0<q^{*}<\bar{q}$. Consider

$$
\begin{aligned}
& \pi\left(q^{*}, \lambda^{*}\right)-\bar{\pi}=\frac{\left[\alpha-\beta w-\beta c\left(\lambda^{*}\right)-\beta C_{e} e\left(\lambda^{*}\right)-\gamma e\left(\lambda^{*}\right)\right]^{2}}{4 \beta} \\
& +C_{e} E_{0}-\frac{[\alpha-\beta w-\beta c(\bar{\lambda})-\gamma e(\bar{\lambda})]^{2}}{4 \beta}=C_{e} E_{0} \\
& -\frac{\beta C_{e} e\left(\lambda^{*}\right)\left[2 \alpha-2 \beta w-2 \beta c\left(\lambda^{*}\right)-\beta C_{e} e\left(\lambda^{*}\right)-2 \gamma e\left(\lambda^{*}\right)\right]}{4 \beta},
\end{aligned}
$$

when $E_{0}$

$$
\geq \frac{\beta C_{e} e\left(\lambda^{*}\right)\left[2 \alpha-2 \beta w-2 \beta c\left(\lambda^{*}\right)-\beta C_{e} e\left(\lambda^{*}\right)-2 \gamma e\left(\lambda^{*}\right)\right]}{4 \beta C_{e}},
$$

$\pi\left(q^{*}, \lambda^{*}\right) \geq \bar{\pi}$

when $E_{0}$

$$
<\frac{\beta C_{e} e\left(\lambda^{*}\right)\left[2 \alpha-2 \beta w-2 \beta c\left(\lambda^{*}\right)-\beta C_{e} e\left(\lambda^{*}\right)-2 \gamma e\left(\lambda^{*}\right)\right]}{4 \beta C_{e}},
$$

$\pi\left(q^{*}, \lambda^{*}\right)<\bar{\pi}$

Proposition 10 shows that, under the carbon quota and transaction policy, when retailers select the same transportation mode, the carbon emission cost causes an increase in product composite cost, and the optimal retail price of products is higher than the price without carbon quota. Therefore, the ordering quantity of retailers is lower than that without carbon quota. However, the increase and decrease in profit directly depend on the initial quota of carbon emission. The initial quota set for an enterprise by the government is equivalent to the "welfare" issued by the enterprise. The enterprise profit is high if the initial quota of carbon emission is high.

\section{Numerical Study}

In order to verify the conclusions above, in this section, a numerical example is provided for mathematics argumentation of the feasibility of the models and to analyze the effect of the retailer price and retailer ordering quantities, and how to select transportation modes 1 and 2. Suppose there is a market

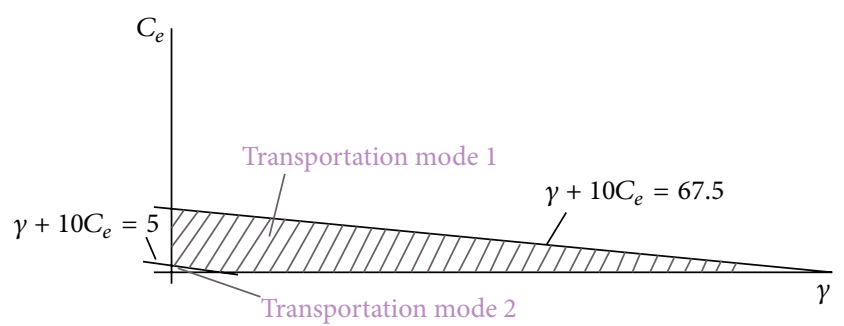

FIgURE 1: Conditions of transportation mode.

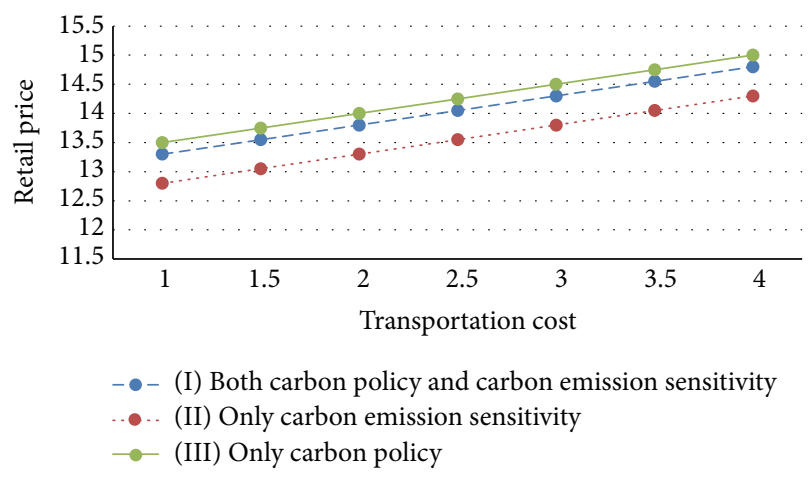

FIGURE 2: Effect of transportation cost on retail prices.

demand $D(p, e)=200-10 p-4 e, C_{e}=1$, and $E_{0}=70$. For transportation mode $1, C_{1}=2, e_{1}=1$. For transportation mode $2, C_{2}=1.5, e_{2}=2$. The procurement price $w=5$.

If we only consider customer emission-sensitive demand (case 1 ), as is mentioned above, $\beta\left(c_{1}-c_{2}\right)=5, \gamma\left(e_{2}-e_{1}\right)=4$, then $\beta\left(c_{1}-c_{2}\right)>\gamma\left(e_{2}-e_{1}\right), \lambda^{*}=0$; transportation mode 2 is better than the other one for the retailer, so $c(\lambda)=c_{2}=1.5$, $e(\lambda)=e_{2}=2$. What is more, we can calculate the optimal retail price and the optimal order quantity; that is, $p^{*}=12.85$ and $q^{*}=63.5$.

If we consider both customer emission-sensitive demand and cap-and-trade policy (case 2$), \beta\left(c_{1}-c_{2}\right)+\beta C_{e}\left(e_{1}-e_{2}\right)=$ $-5, \gamma\left(e_{2}-e_{1}\right)=4, \beta\left(c_{1}-c_{2}\right)<\gamma\left(e_{2}-e_{1}\right)$, and $\lambda^{*}=1$, so transportation mode 1 is better than the other one for the retailer, $c(\lambda)=c_{1}=2, e(\lambda)=e_{1}=1$, and the optimal retail price $p^{*}=13.8$ and the optimal order quantity $q^{*}=58$.

Now, we discuss the effects of the parameters on the transport mode selection problem and the effects of the retailer price and the retailer ordering quantity. Numerical analysis takes three cases of retailer into consideration. Instance I considers both carbon cap-and-trade policy and consumer carbon emission sensibility. Instance II only takes consumer carbon emission sensibility into consideration. Instance III only considers carbon cap-and-trade policy. From Figure 1, we know that the optimal transport mode decision is influenced by the carbon emissions trading price and the consumer carbon emissions sensitivity. Figures 2-5 illustrate the parameters $c_{1}, e_{1}, C_{e}$, and $\gamma$ on the retailer price problem. Figures 6-9 illustrate the parameters $c_{1}, e_{1}, C_{e}$, and $\gamma$ on the retailer ordering quantity problem.

Figure 1 shows that the transportation mode strategy is not only due to consumers' initiative choice of law carbon 


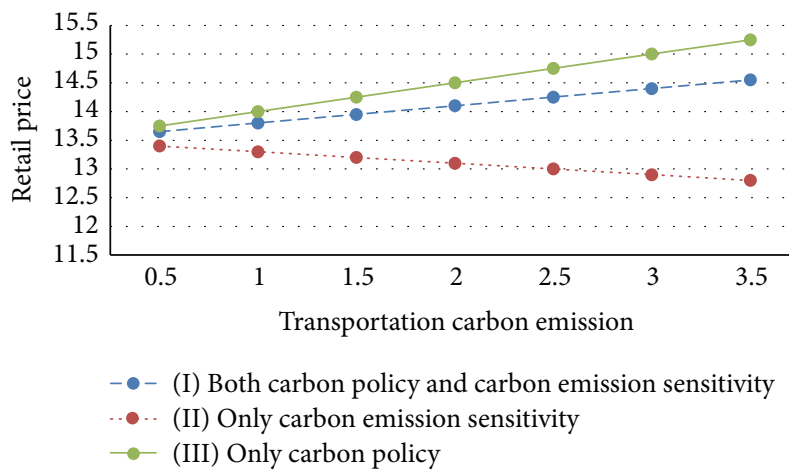

FIGURE 3: Effect of transportation carbon emission on retail prices.

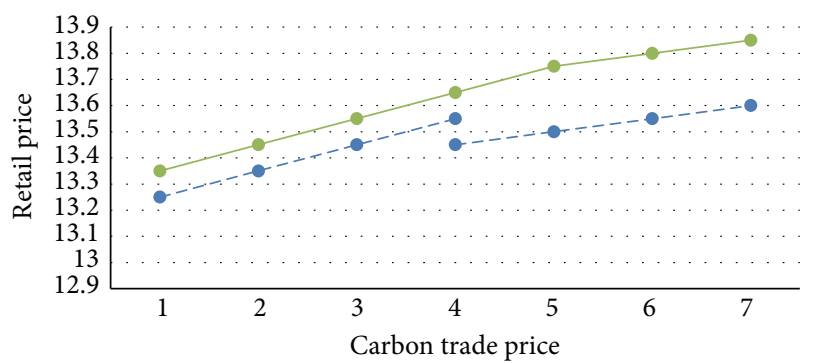

- - (I) Both carbon policy and carbon emission sensitivity - - (III) Only carbon policy

FIGURE 4: Effect of carbon trade price on retail prices.

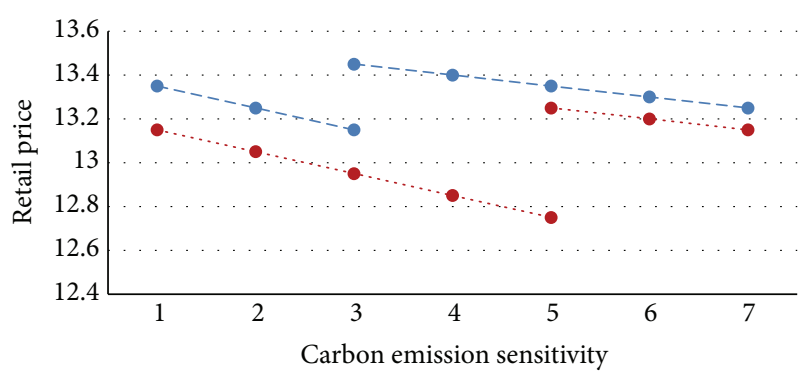

- (I) Both carbon policy and carbon emission sensitivity

-.. (II) Only carbon emission sensitivity

FIGURE 5: Effect of carbon emission sensitivity on retail prices.

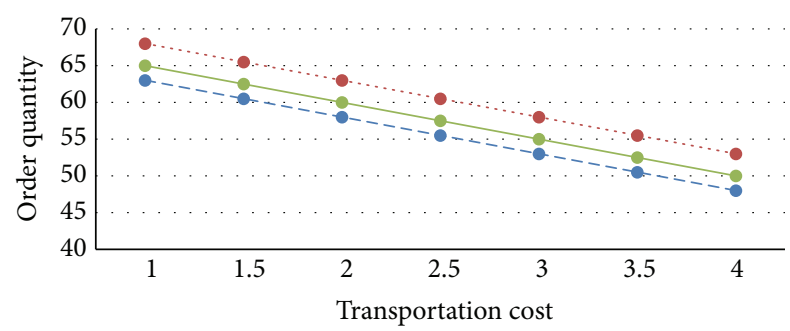

- - (I) Both carbon policy and carbon emission sensitivity

.... (II) Only carbon emission sensitivity

$\rightarrow$ (III) Only carbon policy

Figure 6: Effect of transportation cost on order quantities.

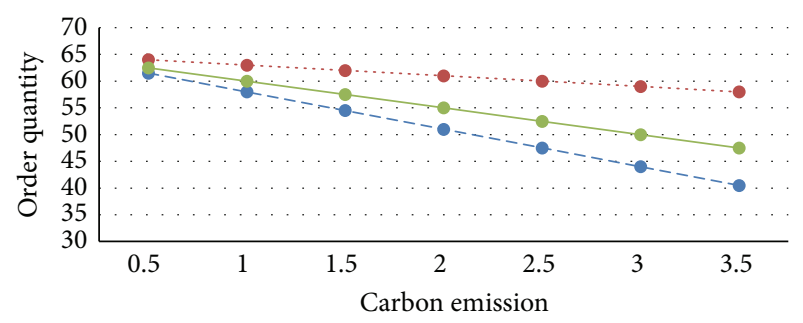

- - (I) Both carbon policy and carbon emission sensitivity

-.. (II) Only carbon emission sensitivity

$\_$(III) Only carbon policy

FIGURE 7: Effect of carbon emission on order quantities.

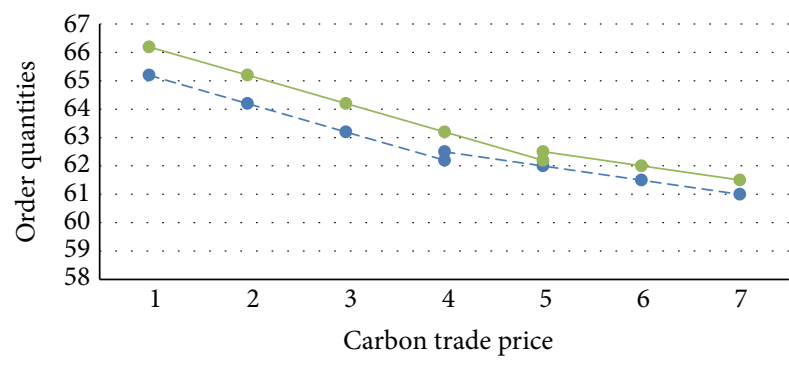

- - (I) Both carbon policy and carbon emission sensitivity

$\rightarrow$ (III) Only carbon policy

FIGURE 8: Effect of carbon trade price on order quantities.

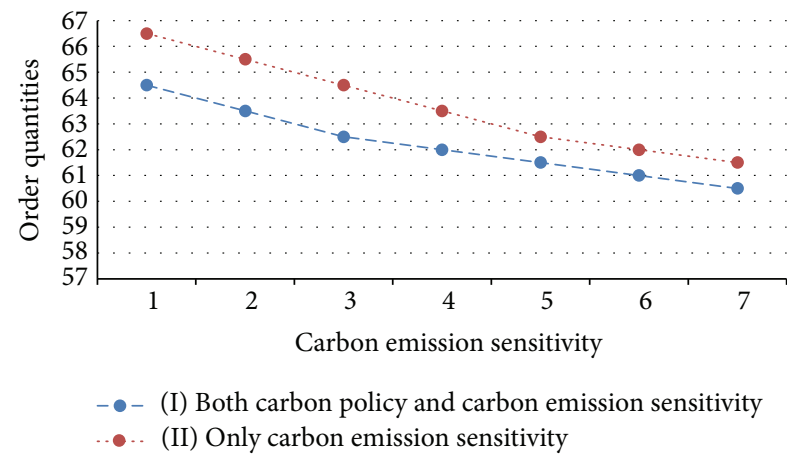

FIGURE 9: Effect of carbon emission sensitivity on order quantities.

products, but also due to the carbon emission reduction policy. $\gamma+10 C_{e}<67.5$ indicates that, under strict carbon policy and consumers' strong carbon sensitivity, the retailer's profit will hardly be affected. When $\gamma+10 C_{e}>5$, that is, $\beta\left(c_{1}-c_{2}\right)+\beta C_{e}\left(e_{1}-e_{2}\right)<\gamma\left(e_{2}-e_{1}\right)$, carbon emission's impact on retailer is more than transportation cost's impact, so, in this situation, transportation mode 2 is the better one.

Figure 2 indicates that retailer optimal retail price is proportional to transportation costs. When the transportation costs remain unchanged, consumers of carbon emission sensitivity own a lower product retail price compared with consumers of noncarbon emission sensitivity. When the government implements the carbon trade policy, product retail price is higher than that without carbon trade policy. 
It is shown in Figure 3 that, for instance I and instance III, retailers are restrained by carbon trade policy, which makes carbon emission costs increase with the increase of carbon emission, as well as retailer optimal retail price. When transportation carbon emission is the same, to promote consumption, consumers' carbon emission sensibility will inhibit the growth speed of retail price compared with instance I. For instance II, within certain range, retailer optimal retail price decreases with the increase of carbon emission. When there is no restraint of carbon trade policy, carbon emission costs do not need to be taken into account. Thus, consumers only own carbon emission sensitivity. To promote consumer market, the greater the carbon emission is, the lower the retailer optimal retail price is.

Suppose consumers carbon sensitivity coefficient $\gamma=1$. It is shown in Figure 4 that, in each segment interval, carbon emission trade price is proportional to product optimal retail price. Segmentation and broken line and rise speed in the figure change according to segment interval because of the change of retailer optimal transportation modes. Compared with instance III, when retailers consider both carbon trade policy and consumers' carbon emission sensibility, retailer selects the low-carbon transportation mode with a lower critical carbon emission trade price. The reason for this is that consumer carbon emission sensibility will promote the selection of retailer low-carbon transportation mode.

Suppose carbon emission trade price $C_{e}=0.2$. When consumers' carbon emission sensibility changes, optimal product retail price also changes, as shown in Figure 5; instance I and instance II both have segmentation; this is because the change of consumers' carbon emission sensibility may cause the change of optimal transportation mode. When the transportation mode is selected, optimal product retail price is inversely proportional to consumers' carbon emission sensibility. For instance I, when $\gamma \geq 3$, retailer selects the transportation mode with low-carbon emission. For instance II, when $\gamma \geq 5$, retailer tends to select the transportation mode with lower carbon emission.

Figure 6 shows that retailer optimal order quantity is inversely proportional to transportation costs. When transportation costs remain unchanged, for retailer with consumers' carbon emission sensibility and government carbon trade policy, optimal order quantity is the lowest, compared with instances II and III.

It is shown in Figure 7 that retailer optimal order quantity decreases with the increase of carbon emission. When consumers own carbon emission sensibility and retailer is restrained by carbon trade policy, the decreasing trend of retailers' optimal order quantity is more obvious.

Suppose consumers' carbon sensitivity coefficient $\gamma=$ 1. It is shown in Figure 8 that when carbon emission trade price increases, retailer optimal order quantity decreases in each segmentation interval. Different segmentation intervals represent different transportation modes and the decreasing speed of retailer optimal order quantity also differs according to segmentation intervals, namely, transportation modes. Compared with instance III, when retailers consider both carbon trade policy and consumers' carbon emission sensibility, retailers select low-carbon transportation mode with a lower critical carbon emission trade price. The reason for this is that consumer carbon emission sensibility can promote the selection of retailer low-carbon transportation mode.

Suppose carbon emissions trade price $C_{e}=0.2$. It is shown in Figure 9 that when consumer carbon emission sensibility increases, optimal product retail price decreases. The images of instance I and instance II both have broken lines. This indicates that when consumer carbon emission sensibility increases, retailers select the transportation mode with low-carbon emission. When retailers are restrained by carbon trade policy, product carbon emission costs are higher and turning point is lower than that without carbon trade policy. Under this condition, it is easier for retailers to select the transportation mode with low-carbon emission.

\section{Conclusions and Future Research}

This study considered the transportation mode selection, pricing, and ordering strategies, and carbon emissionsensitive demands of retailers under the cap-and-trade policy. First, we conducted modeling and algorithms to obtain the optimal ordering, pricing, and transportation mode strategies under the cap-and-trade policy. Then, sensitivity analysis was performed to study the sensitivity of optimal retailer decision and maximum profit for two parameters of transportation mode (i.e., transportation cost and transportation carbon emission), carbon trade price, and initial cap parameters of carbon. The results show that the optimal retail price is proportional to the transportation cost of unit products and the carbon emission transaction price, and the relation of the optimal retail price with the increase and decrease in carbon emission of the unit product transportation depends on the leading position of consumers for carbon emission and price sensitivity. Furthermore, the optimal ordering quantity of retailers is inversely proportional to the unit product transportation cost, carbon emission of unit product transportation, and carbon emission transaction price. The maximum profit of retailers is inversely proportional to the unit product transportation cost and carbon emission transaction price and is proportional to the initial carbon quota of retailers; its relation with the carbon emission transaction price depends on the different values between the initial quota of carbon and actual carbon emission. Finally, by comparing the situations considering and not considering the cap-and-trade policy, and those considering and not considering the retailer optimal decision and maximum profit under carbon emission-sensitive demands, this study analyzed the impact of cap-and-trade policy and carbon emission-sensitive demands. The result shows that the capand-trade policy and preference of consumers for low-carbon products can influence the retailers to select the low-carbon transportation mode. The cap-and-trade policy causes the optimal retail price of products to become higher than the price without the carbon cap and the ordering quantity of retailers to become lower than the quantity without the carbon cap. Retailers can also achieve profit growth under the high-carbon cap. When consumers prefer low-carbon 
products, the optimal retail price, ordering quantity, and retailer profit are all lower than the condition where consumers do not have carbon emission sensitivity.

Based on the environmental awareness of consumers, this study introduced price sensitivity and carbon sensitivity into the demand function for research, making the research environment more consistent with the actual situation. The government not only can strengthen the strategy to enhance customer environmental consciousness to promote carbon emission reduction but also can make different carbonreduction policies for different enterprises.

Our paper can be extended in several directions. First, manufacturers occupy an important position in the entire carbon footprint and most retailers are facing intense competition in a competitive market environment, but only one retailer is discussed in this research, and the retailer can be extended to horizontal competition and vertical development, two aspects. The vertical development can be extended from retailer to supply chains. Similarly, the horizontal competition can be extended from one retailer to two or multiple competing retailers. Another extension of our work is to extend the model by considering the retailer that sells multiple products under emission-sensitive demand. Our study has discussed the model that the demand is assumed to be deterministic and then extend the deterministic demand to stochastic demand to examine the low carbon retailer's optimal strategies. The proposed method and models are hoped to shed light to the future works in the field of retailer transportation mode which is selected in practice.

\section{Parameters and Variables}

$q$ : Ordering quantity or customer demands of retailer

p: $\quad$ Unit retail price of retailer

$E_{0}$ : Initial carbon emission allowances from government

$e_{1}, e_{2}$ : Unit carbon emissions of transport modes

1 and 2 , respectively, $e_{1} \leq e_{2}$

$c_{1}, c_{2}$ : Unit transportation cost of transport modes 1 and 2, respectively, $c_{1} \geq c_{2}$

$e$ : Unit carbon emission quantity of products

$C_{e}$ : Unit price of carbon emission trading

$\lambda: \quad$ Transportation proportion part of transportation mode $1,0 \leq \lambda \leq 1$

$w$ : Unit procurement cost

$\alpha: \quad$ Initial market potential

$\beta$ : $\quad$ Coefficient of retail price impact on demand

$\gamma$ : Coefficient of carbon emission impact on demand

$\pi$ : $\quad$ Profit of retailer.

\section{Conflict of Interests}

The authors declare that there is no conflict of interests regarding the publication of this paper.

\section{Acknowledgment}

The work was supported in part by the ChunHui Plan of Ministry of Education in China (no. S2011012 and no. Z2012017).

\section{References}

[1] H. Cheryl, J. Jeff, and K. Jyllian, "Global-warming warnings," Chemical \& Engineering News, vol. 91, no. 3, article 4, 2014.

[2] IPCC, Climate Change Synthesis Report 2007: Comprehensive Report, IPCC, Geneva, Switzerland, 2007.

[3] K. Chitra, "In search of the green consumers: a perceptual study," Journal of Services Research, vol. 7, no. 1, pp. 173-191, 2007.

[4] Eurostat, Panorama of Transport, 2009, http://epp.eurostat.ec .europa.eu/cache/ITY_OFFPUB/KS-DA-09-001/EN/KS-DA-09001-EN.PDF.

[5] S. Du, J. Zhu, H. Jiao, and W. Ye, "Game-theoretical analysis for supply chain with consumer preference to low carbon," International Journal of Production Research, vol. 53, no. 12, pp. 3753-3768, 2015.

[6] X. Chen, "Optimal retailer's order policy for perishable products with wholesale price updating," Chinese Journal of Management Science, vol. 12, no. 4, pp. 57-63, 2004.

[7] S. Y. Tang and P. Kouvelis, "Supplier diversification strategies in the presence of yield uncertainty and buyer competition," Manufacturing \& Service Operations Management, vol. 13, no. 4, pp. 439-451, 2011.

[8] P. L. Abad, "Optimal pricing and lot-sizing under conditions of perishability and partial backordering," Management Science, vol. 42, no. 8, pp. 1093-1104, 1996.

[9] P. L. Abad, "Optimal pricing and lot-sizing under conditions of perishability, finite production and partial backordering and lost sale," European Journal of Operational Research, vol. 144, no. 3, pp. 677-685, 2003.

[10] N. H. Shah and N. Raykundaliya, "Retailer's pricing and ordering strategy for Weibull distribution deterioration under trade credit in declining market," Applied Mathematical Sciences, vol. 4, no. 21-24, pp. 1011-1020, 2010.

[11] S. W. Shinn and H. Hwang, "Optimal pricing and ordering policies for retailers under order-size-dependent delay in payments," Computers \& Operations Research, vol. 30, no. 1, pp. 3550, 2003.

[12] A. Ekicia, B. Altanb, and O. Ö. Özener, "Pricing decisions in a strategic single retailer/dual suppliers setting under order size constraints," International Journal of Production Research, pp. 112, 2015.

[13] H. Liu and H. Yu, "How does the retailer make pricing decision when consumers have justice reference price," Journal of Systems Science and Systems Engineering, pp. 1-17, 2015.

[14] B. Johansson, "Climate policy instruments and industryeffects and potential responses in the Swedish context," Energy Policy, vol. 34, no. 15, pp. 2344-2360, 2006.

[15] S. Benjaafar, Y. Li, and M. Daskin, "Carbon footprint and the management of supply chains: insights from simple models," IEEE Transactions on Automation Science and Engineering, vol. 10, no. 1, pp. 99-116, 2013.

[16] J. K. Stranlund, "The regulatory choice of noncompliance in emissions trading programs," Environmental and Resource Economics, vol. 38, no. 1, pp. 99-117, 2007. 
[17] A. Ramudhin, A. Chaabane, and M. Paquet, "Carbon market sensitive sustainable supply chain network design," International Journal of Management Science, vol. 5, no. 1, pp. 30-38, 2010.

[18] G. Hua, H. Qiao, and J. Li, "Optimal order lot sizing and pricing with carbon trade," in Proceedings of the 13th International Conference on Enterprise Information Systems (ICEIS '11), pp. 533-536, Beijing, China, June 2011.

[19] X. Chang, H. Xia, H. Zhu et al., "Production decisions in a hybrid manufacturing-remanufacturing system with carbon cap and trade mechanism," International Journal of Production Economics, vol. 162, pp. 160-173, 2015.

[20] L. He, Z. Xu, and Z. Niu, "Joint optimal production planning for complex supply chains constrained by carbon emission abatement policies," Discrete Dynamics in Nature and Society, vol. 2014, Article ID 361923, 14 pages, 2014.

[21] B. C. Murray, R. G. Newell, and W. A. Pizer, "Balancing cost and emissions certainty: an allowance reserve for cap-and-trade," Review of Environmental Economics and Policy, vol. 3, no. 1, pp. 84-103, 2009.

[22] M. R. Shammin and C. W. Bullard, "Impact of cap-andtrade policies for reducing greenhouse gas emissions on U.S. households," Ecological Economics, vol. 68, no. 8-9, pp. 24322438, 2009.

[23] Y. Jiang and D. Klabjan, "Optimal emissions reduction investment under Green House Gas emissions regulations," Northwestern University Working Paper, Northwestern University, Evanston, Ill, USA, 2012, http://www.dynresmanagement.com/uploads/3/3/2/9/3329212/carbonregulations.pdf.

[24] C. S. Tang and S. Zhou, "Research advances in environmentally and socially sustainable operations," European Journal of Operational Research, vol. 223, no. 3, pp. 585-594, 2012.

[25] W. Young, K. Hwang, S. McDonald, and C. J. Oates, "Sustainable consumption: green consumer behaviour when purchasing products," Sustainable Development, vol. 18, no. 1, pp. 20-31, 2010.

[26] P. Mahenc, "Signaling the environmental performance of polluting products to green consumers," International Journal of Industrial Organization, vol. 26, no. 1, pp. 59-68, 2008.

[27] G. A. Blengini and D. J. Shields, "Green labels and sustainability reporting: overview of the building products supply chain in Italy," Management of Environmental Quality, vol. 21, no. 4, pp. 477-493, 2010.

[28] W. Moon, W. J. Florkowski, B. Brückner, and I. Schonhof, "Willingness to pay for environmental practices: implications for eco-labeling," Land Economics, vol. 78, no. 1, pp. 88-102, 2002.

[29] D. Krass, T. Nedorezov, and A. Ovchinnikov, "Environmental taxes and the choice of green technology," Production and Operations Management, vol. 22, no. 5, pp. 1035-1055, 2013.

[30] J. Chen, "Study on supply chain management in a low carbon era," Journal of Systems and Management, vol. 21, no. 6, pp. 721728, 2012.

[31] X. P. Xie, D. Z. Zhao, and Y. J. liu, "Revenue sharing consignment contract of low-carbon supply chain with carbon-emission sensitive demand," Journal of Systems and management, vol. 24, no. 1, pp. 107-115, 2015.

[32] Z. Liu, T. D. Anderson, and J. M. Cruz, "Consumer environmental awareness and competition in two-stage supply chains," European Journal of Operational Research, vol. 218, no. 3, pp. 602-613, 2012.
[33] M. Altmann, "A supply chain design approach considering environmentally sensitive customers: the case of a German manufacturing SME," International Journal of Production Research, vol. 53, no. 21, pp. 6534-6550, 2014.

[34] L. Zhang, J. Wang, and J. You, "Consumer environmental awareness and channel coordination with two substitutable products," European Journal of Operational Research, vol. 241, no. 1, pp. 63-73, 2015.

[35] K. M. R. Hoen, T. Tan, J. C. Fransoo, and G.-J. Van Houtum, "Switching transport modes to meet voluntary carbon emission targets," Transportation Science, vol. 48, no. 4, pp. 592-608, 2014.

[36] K. M. R. Hoen, T. Tan, J. C. Fransoo, and G. J. van Houtum, "Effect of carbon emission regulations on transport mode selection under stochastic demand," Flexible Services and Manufacturing Journal, vol. 26, no. 1-2, pp. 170-195, 2014. 


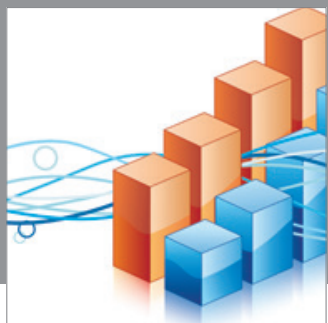

Advances in

Operations Research

mansans

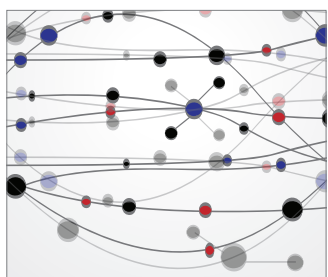

The Scientific World Journal
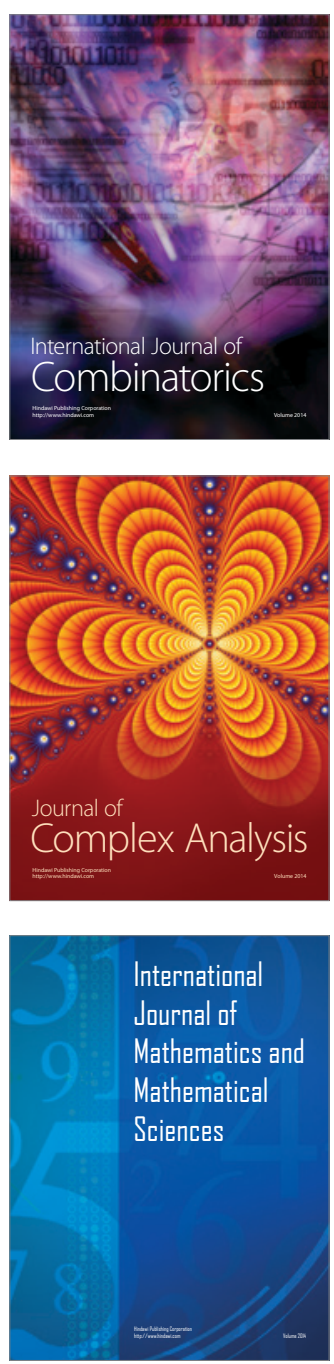
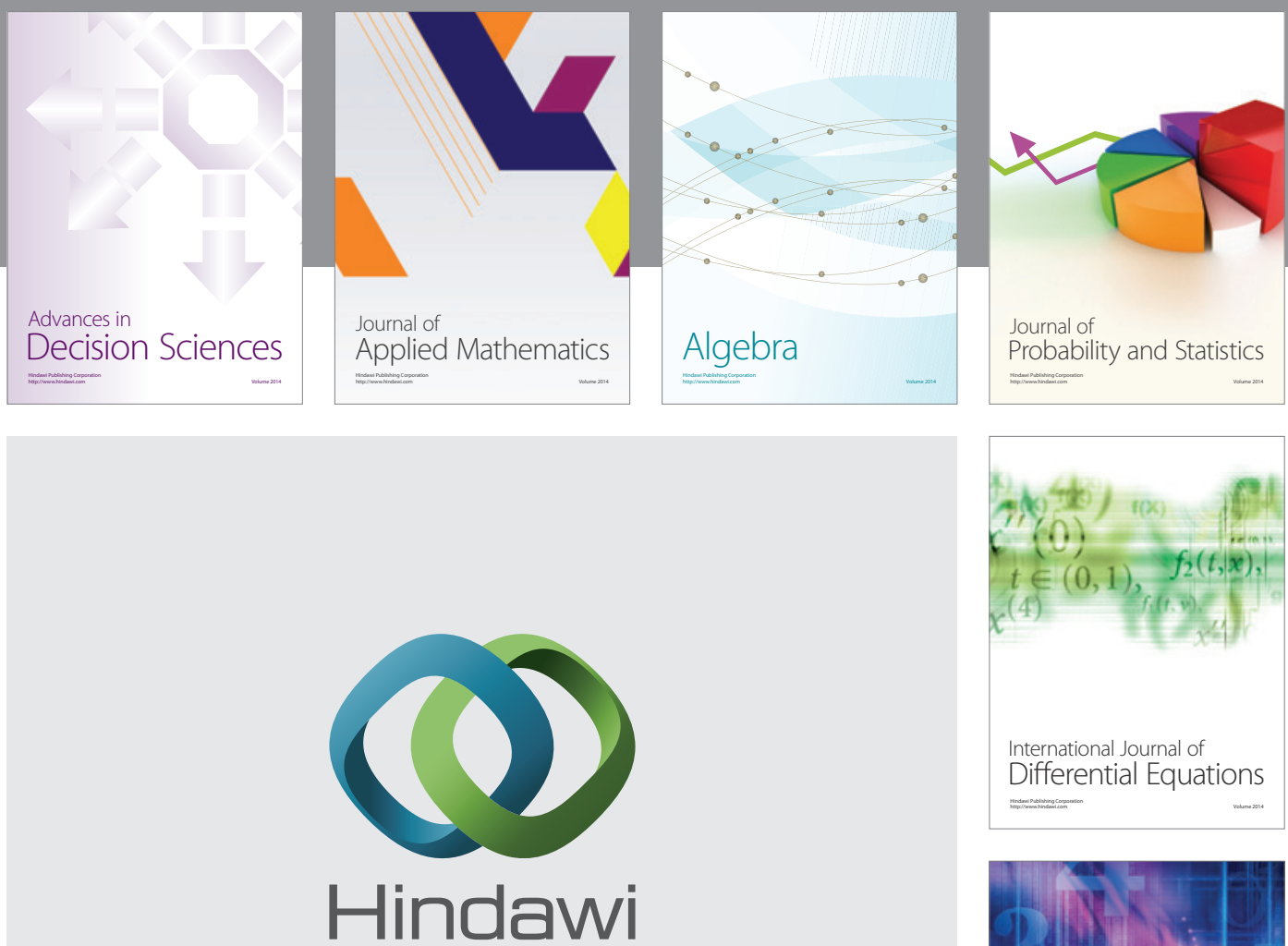

Submit your manuscripts at http://www.hindawi.com
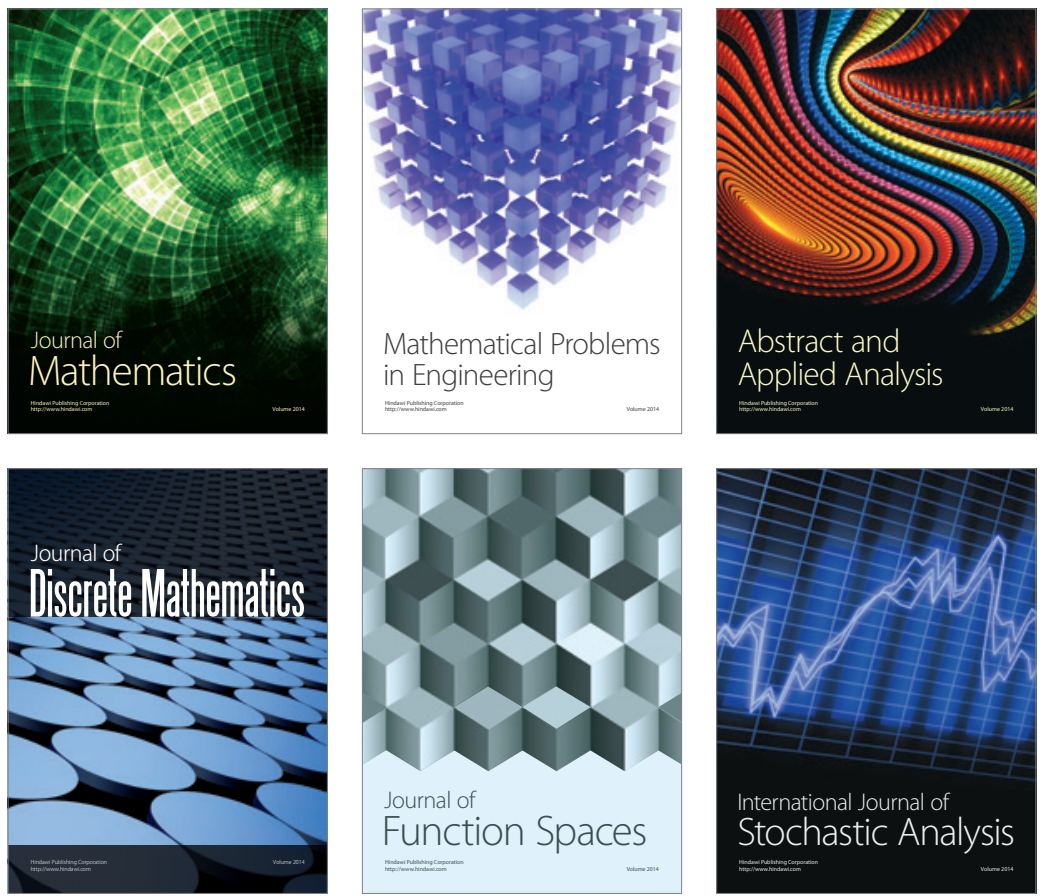

Journal of

Function Spaces

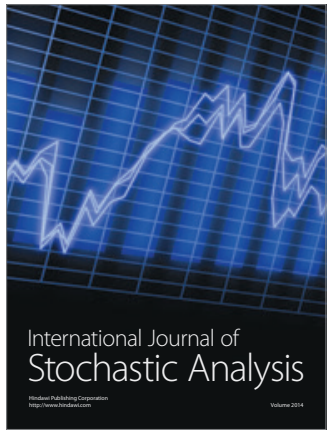

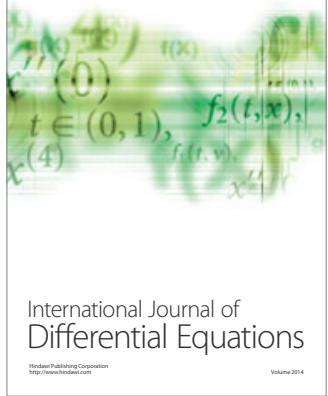
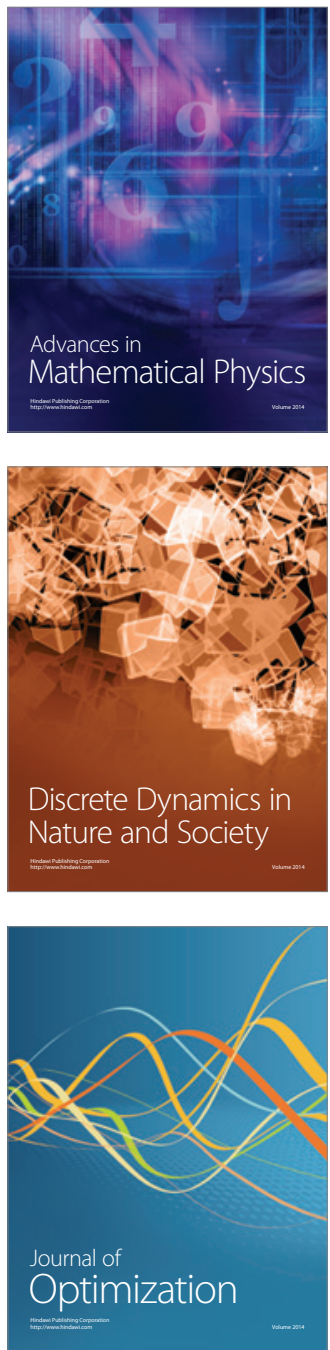